\title{
Arsenic Uptake by Aquatic Macrophyte Spirodela polyrhiza L.: Interactions with Phosphate and Iron
}

M. Azizur Rahman ${ }^{1}$; H. Hasegawa ${ }^{*}{ }^{1}$; K. Ueda ${ }^{1}$; T. Maki ${ }^{1}$; M. Mahfuzur Rahman ${ }^{2}$

${ }^{1}$ Graduate School of Natural Science \& Technology, Kanazawa University, Kakuma, Kanazawa 920-1192, Japan; ${ }^{2}$ Department of Botany, Faculty of Biological Sciences, Jahangirnagar University, Savar, Dhaka-1342, Bangladesh.

*Corresponding author

E-mail: hhiroshi@t.kanazawa-u.ac.jp

Tel/Fax: 81-76-234-4792 


\section{Abstract}

The uptake of arsenate (As(V)) and dimethylarsinic acid (DMAA) by aquatic macrophyte Spirodela polyrhiza L. was investigated to determine the influence of arsenic interaction with $\mathrm{PO}_{4}{ }^{3-}$ and $\mathrm{Fe}$ ions. Plants were grown hydroponically on standard Murashige and Skoog (MS) culture solutions. Arsenic concentrations in Fe-oxide (Fe-plaque) on plant surfaces were determined by citrate-bicarbonate-ethylenediaminetetraacetic acid (CBE) technique. Spirodela polyrhiza L. accumulated 51-fold arsenic from arsenate solution compared to that from DMAA solution with initial concentrations of 4.0 and $0.02 \mu \mathrm{M}$ of arsenic and phosphate, respectively. The arsenate uptake was negatively $(p<0.001)$ correlated with phosphate uptake and positively $(p<0.05)$ correlated with iron uptake. About $56 \%$ of the total arsenic was accumulated into the plant tissues while $44 \%$ was adsorbed on Fe plaque (CBE-extract), when the plants were grown on arsenate solution. The DMAA uptake into the plant was neither affected by the phosphate concentrations nor correlated $(p>0.05)$ with iron accumulation. The results suggest that adsorption of arsenate on Fe plaque of the surface of Spirodela polyrhiza L. contributes to the arsenic uptake significantly. Thus, arsenate uptake in Spirodela polyrhiza L. occurred through the phosphate uptake pathway and by physico-chemical adsorption on Fe-plaques of plant surfaces as well. The Spirodela polyrhiza L. uses different mechanisms for DMAA uptake.

Keywords: Arsenate, DMAA, Uptake, Interactions, Physico-chemical adsorption, Feplaque, Spirodela polyrhiza L. 


\section{Introduction}

Arsenic is an important environmental and health concern due to its known chronic and epidemic toxicity. The main arsenic exposures to humans are through water pathway and food contamination, for instance in Bangladesh [1-3] and West Bengal, India [4] where most of the contaminations originate from natural release from rocks in the aquifer. Geogenic arsenic contamination from aquifer rocks has also been reported in Thailand [5], Vietnam, Inner Mongolia, Greece, Hungary, U.S.A., Ghana, Chile, Argentina and Mexico $[6,7]$. Unfortunately, the traditional chemical and physical remediation techniques are limited due to the pattern of discharge. Hence, Phytoremediation, a plant-based green technology, is proposed as a viable alternative. Its relative inexpensiveness and ecofriendliness have made it an attractive method for water and soil remediation [8]. Some terrestrial plant species such as Agrostis castellana; Agrostis delicatula [9], Bidens cynapiifolia [10], Chinese brake fern (Pteris vittata L.) [11] and silver fern (Pityrogramma calomelanos L.) [12] have been reported to accumulate significant fractions of arsenic from soil. In particular, Chinese brake fern accumulates a formidable quantity of arsenic from soil $[12,13]$ and stores in the fronds [12, 14]. The arsenic hyperaccumulating terrestrial plants are considered for soil remediation. However, restoration of contaminated waters of ponds, lacks, ditches as well as irrigation water remains unresolved. Aquatic macrophytes could be a good tool for the environmentally sound and effective remediation of arsenic contaminated waters $[15,16]$. Hence, we investigated the possible use of duckweed in aquatic phytoremediation.

In the present study, duckweed (Spirodela polyrhiza L.) was selected because of its fast growth, wide distribution, short life span and stability to the large scale environmental changes $[17,18]$. The plant commonly grows in inland small water bodies such as ponds, 
lacks, ditches in Bangladesh and West Bengal, India into which arsenic contaminated water from hand tube wells (used for household necessity) and shallow tube wells (used for irrigation) is drained. Moreover, duckweed (Spirodela polyrhiza L.) grows in the rice fields of south Asian countries where arsenic contaminated groundwater is the main source of irrigation during dry season. The plant is also beneficial to rice cultivation as it suppressed or reduce weed growth in the rice field.

Arsenate and arsenite are bioavailable inorganic forms of arsenic in aquatic systems [19]. The dynamics of arsenate exchange between water and adsorbing colloids are analogous to those of phosphate, though the competition for exchange sites favors phosphate over arsenate [20]. Arsenate and DMAA are the major species of arsenic in oxic aquatic systems [21]. Uptake behavior of these two arsenic species could reflect the influence of inorganic and organic arsenic species and their interactions with $\mathrm{PO}_{4}{ }^{3-}$ and $\mathrm{Fe}$ ions. The comparison between inorganic (arsenate) and organic (DMAA) arsenic species uptake is important because of their limit of toxicity too.

In nature, wetland plants form dense root networks in upper wetland sediments and, under flooded conditions, pump oxygen to their roots for respiration [22]. Thus, oxygenation of the rhizosphere by wetland plants leads to precipitation of iron (oxyhydro)-oxides in the rhizosphere and on the roots of plants [23]. Precipitation of iron (oxyhydro)-oxides on roots of aquatic plants has also been reported in literatures [24]. Due to the high adsorptive affinity of arsenic for iron hydroxides, Fe plaque formation on root surface of aquatic plants might be significant in the uptake of arsenic by the plants. In the present study we reported the uptake of arsenate and DMAA in duckweed (Spirodela polyrhiza L.) and their interactions with $\mathrm{PO}_{4}{ }^{3-}$ and $\mathrm{Fe}$ ions. The contribution of Fe-plaque formation on plant's surfaces in the arsenic uptake has also been discussed. 


\section{Materials and Methods}

\subsection{Conditions for plant cultivation}

The Spirodela polyrhiza L., collected from a rice field in Manikgonj of Dhaka, Bangladesh, was stock-cultured in green house for 2 weeks. Then, the plants were rinsed three times with deionized (DI) water and transferred to growth chamber. In the growth chamber, the experiment was conducted with the conditions being set as 14:10 h light/dark schedule, $100-125 \mu \mathrm{E} \mathrm{m} \mathrm{m}^{-2} \mathrm{~s}^{-1}$ light intensity, 75\% humidity, $22{ }^{\circ} \mathrm{C}$ and $20( \pm 2){ }^{\circ} \mathrm{C}$ temperatures for day and night, respectively.

Modified standard Murashige and Skoog (MS) culture solution was used as growth medium in the experiment (Table 1). The control culture solution contained $0.02 \mu \mathrm{M} \mathrm{PO}_{4}{ }^{3-}$ and other culture solutions were prepared by modifying the $\mathrm{PO}_{4}{ }^{3-}$ concentration to 100 or $500 \mu \mathrm{M}$. Three test concentrations $(1.0,2.0$ and $4.0 \mu \mathrm{M})$ of either arsenate or DMAA were added to the modified MS culture solutions. The $\mathrm{pH}$ of the solution was adjusted to 6.0.

Before inoculation, Spirodela polyrhiza L. from the stock-culture were rinsed for three times with deionized (DI) water. About $100 \mathrm{ml}$ of culture solution was taken into 200-ml polystylene test vessels (118 x 86 x $60 \mathrm{~mm})$. About 120 individual plants were inoculated in each of the test vessels. The experiment was arranged following the randomized design (RD) with three replicates. Stock solutions of arsenate and DMAA were made by dissolving $\mathrm{Na}_{2} \mathrm{HAsO}_{4} \cdot 7 \mathrm{H}_{2} \mathrm{O}$ and $\left(\mathrm{CH}_{3}\right)_{2} \mathrm{AsO}_{2} \mathrm{Na} \cdot 3 \mathrm{H}_{2} \mathrm{O}$ in DI water, respectively. Arsenic stock solutions were added to the cultures before inoculation. The plants were grown for 12 days. Changes in the volume of cultures from evaporation and accumulation were compensated by adding DI water every 2 days throughout the experiment. 


\subsection{Iron plaque induction}

A separate experiment was conducted to investigate the role of iron plaque on arsenic uptake in Spirodela polyrhiza L. Plants were grown in $1.5 \mathrm{~L}$ of DI water for $24 \mathrm{~h}$ before iron induction to minimize interferences from other elements with iron. They were then, transferred into $1 \mathrm{~L}$ of the MS solution containing $0.36 \mathrm{mM}$ of iron as $\mathrm{FeSO}_{4} \cdot 7 \mathrm{H}_{2} \mathrm{O}$ and grown for 2 days. The $\mathrm{pH}$ of solution was adjusted to 6.0 using either $0.1 \mathrm{M} \mathrm{KOH}$ or 0.1 M HCl. The specified standard concentration of phosphate for MS culture solution was not modified. After 2 days in high iron medium, plants were inoculated into MS culture solution for 12 days as described in the previous section, with $6.0 \mu \mathrm{M}$ of either arsenate or DMAA.

\subsection{CBE-extraction of Fe-plaques}

Iron plaques from plant surfaces were extracted using citrate-bicarbonateethylenediaminetetraacetate (CBE)-technique, a modification of dithionite-citratebicarbonate (DCB)-extraction method of Taylor and Crowder [25] and Otte et al. [26]. The CBE solution was prepared from $0.03,0.125$ and $0.050 \mathrm{M}$ of sodium citrate, sodium bicarbonate and EDTA, respectively. Plants were treated with $30 \mathrm{ml}$ of CBE solution for 60 min. at room temperature. The plants were then, rinsed with DI water for 3 times, and the rinsed water was added to the CBE-extracts to make a total volume of $50 \mathrm{ml}$.

\subsection{Sample preparation and chemical analysis}

All plants were harvested after 12 days of inoculation. After rinsing with DI water for four times, the plant samples were kept on clean absorbent paper to remove the water from the plant surfaces. The samples were dried at $65{ }^{\circ} \mathrm{C}$ until they reached a constant weight. Then, $0.10-0.20 \mathrm{~g}$ of dried samples was taken into 50-ml polyethylene tubes (DigiTubes, SCP Science, Canada) for digestion. Five $\mathrm{ml}$ of $65 \% \mathrm{HNO}_{3}$ were added to the sample and 
then, left to incubate for 12 hours. The samples were heated on a heating block (DigiPREP, SCP Science, Canada) at $95{ }^{\circ} \mathrm{C}$ for 2 hours. After cooling to room temperature, $3 \mathrm{ml}$ of $30 \%$ hydrogen peroxide were added and the samples were heated again at $105{ }^{\circ} \mathrm{C}$ for $20 \mathrm{~min}$. Then, the digests were diluted to $10 \mathrm{ml}$ with DI water and taken into 15-ml polyethylene bottles (HDPE, NALGENE ${ }^{\circledR}$, Nalge Nunc International, Rochester, NY) in readiness for analysis.

Arsenic and iron were analyzed using graphite-furnace atomic absorption spectrometer (GF-AAS, Z-8100, Hitachi, Japan). For the determination of arsenic, $5 \mu \mathrm{L}$ of $0.05 \mathrm{M}$ nickel nitrate was added to a $10-\mu \mathrm{L}$ sample into the cuvette as matrix modifier. Certified standard reference material 1573a (tomato leaf from NIST, USA) was used to check the accuracy of analysis. Arsenic concentration in certified reference material was $0.112 \pm 0.004 \mu \mathrm{g} \mathrm{g}^{-1}$ while the measured arsenic concentration was $0.123 \pm 0.009 \mu \mathrm{g} \mathrm{g}^{-1}$. The concentrations detected in all samples were above the instrumental limits of detection $(\geq$ $0.01 \mu \mathrm{M}$ in samples in water). Total phosphate was determined spectrophotometrically [27].

All chemical reagents used in this experiment were of analytical grade. Glassware and dishes were washed with detergent solution, $3 \mathrm{M} \mathrm{HCl}$ and finally rinsed with DI water for eight times before use. In each analytical batch, at least two reagent blanks and three replicate samples were included.

\subsection{Data analysis}

Bioaccumulation of arsenic by Spirodela polyrhiza L. was determined on dry weight basis [18]. The experimental data were statistically analyzed for mean separation of different arsenic treatments according to the least significant difference (LSD) at 5\% level by IRRI- 
STAT 4.0 for windows (Developed by the Biometrics unit, IRRI, Philippines) and the Pearson correlation coefficient (r) was calculated by SPSS ${ }^{\circledR}$ statistical package.

\section{Results and Discussion}

\subsection{Accumulation of As species in S. polyrhiza L.}

The accumulation of arsenic in Spirodela polyrhiza L. from arsenate treatment is presented in Fig. 1., where as the accumulation from DMAA treatment is presented in Fig. 2. The results show that Spirodela polyrhiza L. accumulated about 51-fold arsenic, when the plants were inoculated in arsenate solution compared to that in DMAA solution. Arsenic contents in tissues had a strong positive correlation with the initial concentrations of arsenate in culture solutions ( $r=0.979 ; p<0.001$ at $95 \%$ confidence interval).

\subsection{Influence $\mathrm{PO}_{4}{ }^{3-}$ on As uptake}

The accumulation of arsenic in Spirodela polyrhiza L. decreased significantly with the increase of the phosphate concentration in the culture solutions for all three arsenate concentrations (Fig. 1). When the concentration of $\mathrm{PO}_{4}{ }^{3-}$ in the culture solution was increased from 0.02 to $500 \mu \mathrm{M}$ with a constant arsenate concentration $(4.0 \mu \mathrm{M})$, arsenic accumulation into the Spirodela polyrhiza L. decreased by $68 \%$. The result implies the suppression of arsenic uptake in Spirodela polyrhiza L. by phosphate from arsenate solution.

Mkandawire and Dudel [15] reported 0.26 and $1.45 \mu \mathrm{mol} \mathrm{g}^{-1}$ dry weight of arsenic accumulation in fronds of Lemna gibba L. (lesser duckweed), when the $\mathrm{PO}_{4}{ }^{3-}$ concentrations in arsenate treated culture solution were 421 and $0.014 \mu \mathrm{M}$, respectively. In another study, Mkandawire et al. [18] observed that arsenic accumulation decreased by 28-32\%, when $\mathrm{PO}_{4}{ }^{3-}$ concentration in arsenate treated culture solution was increased from 
0.014 to $421 \mu \mathrm{M}$. The impact of increasing phosphate concentration in culture solutions was similar to that of present experiment. Thus, the magnitude of arsenic accumulation in Spirodela polyrhiza L. in relation to $\mathrm{PO}_{4}{ }^{3-}$ concentrations in culture solution with arsenate is comparable with that in Lemna gibba L. This might be because $\mathrm{AsO}_{4}{ }^{3-}$ is a sorption analog of $\mathrm{PO}_{4}{ }^{3-}$ and competes with it for uptake carriers in the plasmalemma [18]. Mkandawire and Dudel [15] proposed the arsenate uptake in Lemna gibba L. might occur through the phosphate uptake pathway due to similar chemical behavior of $\mathrm{AsO}_{4}{ }^{3-}$ and $\mathrm{PO}_{4}{ }^{3-}$. The present findings suggest the same for Spirodela polyrhiza L.

In contrast, arsenic accumulation was not affected with the increase of phosphate concentration in DMAA solution (Fig. 2). The results imply that the arsenate uptake into the aquatic macrophyte is related to the phosphate concentration in the culture solution, while DMAA uptake was not.

\subsection{Effect of As species on $\mathrm{PO}_{4}{ }^{3-}$ uptake}

Phosphorus uptake in Spirodela polyrhiza L. decreased significantly $(p<0.001)$ with the increase of arsenate concentrations in culture solutions, while DMAA had no significant effect $(p>0.05)$ on its uptake. Pearson correlation analysis revealed a strong negative relationship between the arsenate concentration in culture solutions and phosphate concentration in plant tissues ( $\mathrm{r}=-0.994 ; p<0.001$ at $95 \%$ confidence interval). On the other hand, the correlation was not significant $(r=-0.220 ; p>0.05$ at $95 \%$ confidence interval) for DMAA. De La Rosa et al. [28] reported the reduction of phosphate uptake into tumbleweed (Salsola kali), when the plant was exposed to arsenate.

Figure 3 shows the relationship between arsenic and phosphate concentrations in Spirodela polyrhiza L. The correlation between arsenic and phosphate concentrations $(\mathrm{r}=$ 
$-0.982 ; p<0.001$ at $95 \%$ confidence interval) in Spirodela polyrhiza L. was stronger and negative, when the plants were exposed to arsenate solution (Fig. 3a). On the other hand, the correlation was very poor $(r=-0.281 ; p>0.05$ at $95 \%$ confidence interval), when the plants were exposed to DMAA solution (Fig. 3b). The results suggest that the phosphate uptake into the aquatic macrophyte might be inhibited by arsenate while its uptake was not influenced by DMAA. The reduction of phosphate uptake might be due to the desorption of arsenate from iron plaque of plant surfaces. Barrow (29) investigated As(V) and P competitive adsorption in soil and found that, though As(V) desorbed some previously adsorbed $\mathrm{P}$, a substantial portion of the bound $\mathrm{P}$ was not displaced by As(V).

\subsection{Influence of Fe on As species uptake}

Iron concentrations were positively correlated with those of arsenic $(r=0.662 ; p=0.019$ at 95\% confidence interval) in Spirodela polyrhiza L. exposed to arsenate solution. On the other hand, iron concentrations did not correlate with those of arsenic $(r=0.031 ; p=0.923$ at 95\% confidence interval) in plants exposed to DMAA solution. Robinson et al. [30] also reported positive correlation between arsenic and iron concentrations in aquatic plants because arsenic could be adsorbed by iron oxides on plant surfaces. However, which species of arsenic predominated in such adsorption was not clear from their study. The present study suggest that inorganic arsenic species are more likely to be adsorbed on Fe plaques on Spirodela polyrhiza L. Blute et al. [31] reported that arsenate correlated positively with iron in plaque and negatively with iron adsorbed on the roots of Typha latifolia (cattail) growing on arsenic contaminated wetland sediments. According to Blute et al. [31], the ferric plaque was predominantly $\mathrm{Fe}(\mathrm{III})$ oxyhydroxide, and arsenate accounted for $80 \%$ of the total adsorbed arsenic. Adsorption of arsenic on ferric iron inhibited the mobility of arsenic into the roots. Another report [32] suggested the same mechanism for arsenic retention by rice root. 


\subsection{Influence of $\mathrm{PO}_{4}{ }^{3-}$ on As adsorption on Fe plaque of plant surfaces}

Arsenic and iron concentrations in plants grown in solution with arsenate and lower phosphate were highly correlated ( $\mathrm{r}=0.994 ; \mathrm{p}<0.001$ at $95 \%$ confidence interval) (Fig. 4a). But they were not significantly correlated when the plants were grown in solution with higher phosphate $\left(r=-0.220\right.$ and -0.461 for 100 and $500 \mu \mathrm{M}$ of $\mathrm{PO}_{4}{ }^{3-}$ in solutions, respectively; $p>0.05$ ) and the same arsenic species (Fig. 4b, 4c). This might attribute to the adsorption of arsenate on iron plaques of plant surfaces in lower phosphate solution, which was desorbed by phosphate in higher phosphate solution.

The adsorption of phosphate on iron plaque has been reported by Zhang et al. [33]. They demonstrated that the amounts of phosphorus accumulated in iron plaque were correlated positively to the amount of iron plaque on roots. Therefore, iron plaque on roots might act as a phosphorus pool. Beside this, there are contradictory reports on the effects of iron plaque on phosphorus uptake by plant $[26,34,35]$. The reasons for such opposite results that iron plaque affect phosphorus uptake may be due to the different plant species and the amount of iron plaque, especially to the latter. Zhang et al. [33] reported that the phosphorus concentration in shoots of rice increased by $72 \%$ with the increase of iron

plaque from 0.22 to $24.5 \mathrm{~g}^{-\mathrm{kg}}$ dry root weight. But higher plaque deposition (28.3 $\mathrm{g}^{-\mathrm{kg}} \mathrm{dry}$ root weight) on rice root surface decreased phosphate concentration.

Though Zhang et al. [33] demonstrated the adsorption of phosphate on Fe plaques of plant's root surface the role of phosphate is not clear from their study. The present study suggests that arsenate adsorbed on iron plaques of plant surfaces might be desorbed by phosphate at higher concentration. 


\subsection{Comparison between internalized and surface adsorbed As}

Physico-chemical adsorption, a different mechanism for arsenic accumulation into aquatic plants, has been proposed in the literature (Robinson et al. [30]. In this mechanism, suspended oxides of iron (Fe plaques) on the root and lower surface of the fronds of aquatic plants adsorb arsenic.

To understand the arsenate adsorption on iron plaques, iron plaques were induced on Spirodela polyrhiza L. surfaces before expose them to the arsenic species. Arsenic concentrations in plant tissues and iron plaques (CBE-extracts) were determined separately. Results showed that when Spirodela polyrhiza L. was exposed to $6.0 \mu \mathrm{M}$ arsenate, $0.86 \pm 0.06 \mu \mathrm{mol} \mathrm{g}{ }^{-1}$ dry weight of arsenic was adsorbed on iron plaques of plant surfaces. On the other hand, arsenic concentration was $1.08 \pm 0.12 \mu \mathrm{mol} \mathrm{g}^{-1}$ dry weight into the plant tissues (Table 2). The result shows that about $56 \%$ of the total arsenic is distributed into the plant tissues compared to $44 \%$ in Fe-plaques. However, significantly higher concentration of iron (547 $\pm 5 \mu \mathrm{M} \mathrm{g}^{-1}$ dry weight) in CBE-extracts compared with plant tissues $\left(69.3 \pm 1.0 \mu \mathrm{M} \mathrm{g}^{-1}\right.$ dry weight) (Table 2) confirms the formation of iron plaques on plant surfaces. The current results imply that adsorption of arsenate on Fe plaque of the surface of Spirodela polyrhiza L. contributes to arsenate uptake significantly.

There was no significant correlation between DMAA and phosphate concentrations in Spirodela polyrhiza L. (Fig. 3b). Moreover, DMAA and iron concentrations in plants did not correlate significantly $(p>0.05)$ in neither low nor high phosphate solutions (Fig. 4A, 4B and 4C). It suggests that the accumulation of DMAA might not correlate with phosphate accumulation. Arsenic concentrations in Fe-plaques and plant tissues were low and did not differ significantly, when the plants were exposed to DMAA (Table 2). The 
results imply that DMAA less adsorbed to Fe-plaques on the plant surface and Fe has more effect on As uptake from inorganic arsenic sources.

\section{Conclusion:}

The results of the present study show that not only internalized, but also surface adsorbed arsenic (mostly arsenate) contributes significantly to the total amount of arsenic uptake in aquatic macrophyte Spirodela polyrhiza L. Thus, it could be suggest that arsenic uptake in Spirodela polyrhiza L. occurred through the phosphate uptake pathway as well as by physico-chemical adsorption on Fe-plaques of plant's surfaces. The arsenate uptake in the plant is related to the $\mathrm{Fe}$ ion and phosphate concentrations in culture medium while DMAA was not. It is well reported in many previous studies that arsenate compete with phosphate for uptake carriers in the plasmalemma, which is also consistent to the present study. But the current study reports that higher phosphate concentration in the culture medium might desorbs arsenate from iron plaques of plant surfaces.

\section{Acknowledgements:}

This research was supported partly by Grants-in-Aid for Scientific Research (18510071) from the Japan Society for the Promotion of Science, and the Steel Industry Foundation for the Advancement of Environmental Protection Technology, Japan.

\section{References:}

[1] M.A. Fazal, T. Kawachi, E. Ichio, Validity of the latest research findings on causes of groundwater arsenic contamination in Bangladesh. Water Inter. 26 (2001) 380-389.

[2] A.H. Smith, E.O. Lingas, M. Rahman, Contamination of drinking water by arsenic in Bangladesh: a public health emergency. Bull. World Health Organ. 78 (2000) 10931103. 
[3] C. Hopenhayn, Arsenic in drinking water: Impact on human health. Elements 2 (2006) 103-107.

[4] U.K. Chowdhury, B.K. Biswas, T.R. Chowdhury, G. Samanta, B.K. Mandal, G.C. Basu, C.R. Chanda, D. Lodh, K.C. Saha, S.K. Mukherjee, S. Roy, S. Kabir, Q. Quamruzzaman, D. Chakraborti, Groundwater arsenic contamination in Bangladesh and West Bengal, India. Environ. Health Perspect. 108 (2000) 393-397.

[5] P. Visoottiviseth, K. Francesconi, W. Sridokchan, The potential of Thai indigenous plant species for the phytoremediation of arsenic contaminated land. Environ. Pollut. 118 (2002) 453-461.

[6] P. O’Neill, Arsenic. In: Alloway BJ, ed. Heavy Metals in Soils. Springer, (1995) 105121.

[7] P.L. Smedley, D.G. Kinniburgh, A review of the source, behaviour and distribution of arsenic in natural waters. Appl. Geochem. 17 (2002) 517-568.

[8] I. Raskin, P.B.A. Nanda-Kumar, S. Dushenkov, D.E. Salt, B.D. Ensley, Removal of radionuclides and heavy metals from water and soil by plants. OECD Document on Bioremediation, (1994) 345-354.

[9] T. De Koe, Agrostic castellana and Agrostis delicatula on heavy metal and arsenic enriched sites in NE Portugal. Sci. Total Environ. 145 (1994) 103-109.

[10] J. Bech, C. Poschenrieder, M. Llugany, J. Barcelo, P. Tume, F.J. Toloias, As and heavy metal contamination of soil and vegetation around a copper mine in Northern Peru. Sci. Total Environ. 203 (1997) 83-91.

[11] L.Q. Ma, K.M. Komar, C. Tu, W. Zhang, Y. Cai, E.D. Kennelley, A fern that hyperaccumulates arsenic. Nature (2001) 409, 579.

[12] P.A. Gulz, S.K. Gupta, R. Schulin, Arsenic accumulation of common plants from contaminated soils. Plant soil 272 (2005) 337-347. 
[13] K. Komar, L.Q. Ma, D. Rockwood, A.A. Syed, Identification of arsenic tolerant and hyperaccumulating plants from arsenic contaminated soils in Florida. Agronomy Abstract (1998) 343.

[14] C. Tu, L.Q. Ma, B. Bondada, Arsenic accumulation in the hyperaccumulator Chinese brake and its utilization potential for phytoremediation. Environ. Qual. 31 (2002) $1671-1675$.

[15] M. Mkandawire, E.G. Dudel, Accumulation of arsenic in Lemna gibba L. (duckweed) in tailing water of two abandoned uranium mining sites in Saxony, Germany. Sci. Total Environ. 336 (2005) 81-89.

[16] B. Robinson, C. Duwig, N. Bolan, M. Kannathasan, A. Saravanan, Uptake of arsenic by New Zealand watercress (Lepidium sativum). Sci. Total Environ. 301 (2003) 6773.

[17] E. Landolt, R. Kandeler, The family Lemnaceae: a monographic study. Volume 2. Veroeffentligunchen des geobotanisches Institutes der ETH Zurich, Stiftung Rubel, Zurich. 95 (1987) 638.

[18] G.D. Lemon, U. Posluszny, B.C. Husband, Potential and realized rates of vegetative reproduction in Spirodela polyrhiza, Lemna minor, and Wolffia borealis. Aqu. Bot. 70 (2001) 79-87.

[19] O.I. Sizova, V.V. Kochetkov, S.Z. Validov, A.M. Boronin, P.V. Kosterin, Y.V. Lyubun, Arsenic-contaminated soils: genetically modified Pseudomonas spp. and their arsenic-phytoremediation potential. Soils Sed. 2 (2002) 19 -23.

[20] M. Mkandawire, Y.V. Lyubun, P.V. Kosterin, E.G. Dudel, Toxicity of arsenic species to Lemna gibba L. and the influence of phosphate on arsenic bioavailability. Environ. Toxicol. 19 (2004) 26-35. 
[21] H. Hasegawa, M. Matsui, S. Okamura, M. Hojo, N. Iwasaki, Y. Sohrin, Arsenic speciation including 'Hidden’ arsenic in natural waters. Appl. Organometal. Chem. 13 (1999) 113-119.

[22] W. Armstrong, Aeration in higher plants. Adv. Bot. Res. 7 (1979) 226-332.

[23] N.K. Blute, D.J. Brabander, H.F. Hemond, S.R. Sutton, M.G. Newville, M.L. Rivers, Arsenic sequestration by ferric iron plaque on cattail roots. Environ. Sci. Technol. 38 (2004) 6074-6077.

[24] C.M. Hansel, S. Fendorf, S. Sutton, M. Newville, Characterization of Fe plaque and associated metals on the roots of mine-waste impacted aquatic plants. Environ. Sci. Technol. 35 (2001) 3863-3868.

[25] G.J. Taylor, A. Crowder, Use of DCB technique for extraction of hydrous iron oxides from roots of wetland plants. American J. Bot. 70 (1983) 1254-1257.

[26] M.L. Otte, M.J. Dekkers, J. Rozema, R.A. Broekman, Uptake of arsenic by Aster tripolium in relation to rhizosphere oxidation. Canadian J. Bot. 69 (1991) 2670-2677.

[27] S.C. Lenore, E.G. Arnold, D.E. Andrew, Standard methods for the examination of water and wastewater, $20^{\text {th }}$ edition. APHA, AWWA and WEF. USA. (1998)

[28] G. De La Rosa, J.G. Parsons, A.M. Martinez, J.R. Peralta-videa, J.L. GardeaTorresdey, Spectroscopic study of the impact of arsenic speciation on arsenic/phosphorus uptake and plant growth in Tumbleweed (Salsola kali). Environ. Sci. Technol. 40 (2006) 1991-1996.

[29] N.J. Barrow, On the displacement of adsorbed anions from soil: 2. Displacement of phosphate by arsenate, Soil Sci. 117 (1974) 28-33.

[30] B. Robinson, N. Kim, M. Marchetti, C. Moni, L. Schroeter, C. Dijssel, G. van den Milne, B. Clothier, Arsenic hyperaccumulation by aquatic macrophytes in the Taupo Volcanic Zone, New Zealand. Environ. Exp. Bot. 58 (2006) 206-215. 
[31] N.K. Blute, D.J. Brabander, H.F. Hemond, S.R. Sutton, M.G. Newville, M.L. Rivers, Arsenic sequestration by ferric iron plaque on cattail roots. Environ. Sci. Technol. 38 (2004) 6074-6077.

[32] Z. Chen, Y.G. Zhu, W.J. Liu, A.A. Meharg, Direct evidence showing the effect of root surface iron plaque on arsenite and arsenate uptake into rice (Oryza sativa) roots. New Phytol. 165 (2005) 91-97.

[33] X. Zhang, F. Zhang, D. Mao, Effect of iron plaque outside roots on nutrient uptake by rice (Oryza sativa L.): Phosphorus uptake. Plant Soil 209 (1999) 187-192.

[34] A.A. Crowder, L. St.-Cyr, Iron oxide plaque on wetland roots. Trends Soil Sci. 1 (1991) 315-329.

[35] S. Greipsson, Effect of iron plaque on roots of rice on growth of plants in excess zinc and accumulation of phosphorus in plant in excess copper or nickel. J. Plant Nutr. 18 (1995) 1659-1665. 
Table 1: Modified $^{\mathrm{a}}$ murashige \& skoog (MS) nutrients for Spirodela polyrhiza L. hydroponic culture medium

\begin{tabular}{|c|c|}
\hline Nutrients & Concentration $\left(\mathrm{mg} \mathrm{l}^{-1}\right)$ \\
\hline $\mathrm{KNO}_{3}$ & 1900 \\
\hline $\mathrm{NH}_{4} \mathrm{NO}_{3}$ & 1650 \\
\hline $\mathrm{CaCl}_{2} \cdot 2 \mathrm{H}_{2} \mathrm{O}$ & 440 \\
\hline $\mathrm{MgSO}_{4} \cdot 7 \mathrm{H}_{2} \mathrm{O}$ & 370 \\
\hline $\mathrm{K}_{2} \mathrm{HPO}_{4}$ & Modified $^{\text {a }}$ \\
\hline $\mathrm{FeSO}_{4} \cdot 7 \mathrm{H}_{2} \mathrm{O}$ & 27.80 \\
\hline $\mathrm{MnSO}_{4} \cdot 5 \mathrm{H}_{2} \mathrm{O}$ & 22.30 \\
\hline $\mathrm{ZnSO}_{4} \cdot 7 \mathrm{H}_{2} \mathrm{O}$ & 8.60 \\
\hline $\mathrm{H}_{3} \mathrm{BO}_{3}$ & 6.20 \\
\hline KI & 0.83 \\
\hline $\mathrm{Na}_{2} \mathrm{MoO}_{4} \cdot 2 \mathrm{H}_{2} \mathrm{O}$ & 0.25 \\
\hline $\mathrm{CuSO}_{4} \cdot 5 \mathrm{H}_{2} \mathrm{O}$ & 0.025 \\
\hline $\mathrm{CoCl}_{2} \cdot 6 \mathrm{H}_{2} \mathrm{O}$ & 0.025 \\
\hline $\mathrm{Na}_{2}$-EDTA & 37.30 \\
\hline
\end{tabular}

${ }^{a}$ The control solution contained $0.02 \mu \mathrm{M} \mathrm{PO}{ }_{4}{ }^{3-}$ and the modifications of the solutions were 100 and $500 \mu \mathrm{M}$ of $\mathrm{PO}_{4}{ }^{3-}$. The $\mathrm{pH}$ of the solution was adjusted to 6.0 . 
Table-2: Arsenic and iron concentrations into the tissues of Spirodela polyrhiza L. and Fe-plaques of the plant surfaces grown for 12 days in solution containing 6.0 $\mu \mathrm{M}$ arsenic $^{\mathrm{a}}$

\begin{tabular}{ccccc}
\hline As treatments & \multicolumn{2}{c}{$\mu$ mol As (g dry weight) } & \multicolumn{2}{c}{$\mu$ mol Fe (g dry weight) ${ }^{-1}$} \\
\cline { 2 - 5 } in solutions & Plant tissues & CBE-extracts & Plant tissues & CBE-extracts \\
\hline Control & $0.04 \pm 0.01 \mathrm{c}$ & $0.02 \pm 0.00 \mathrm{c}$ & $65.2 \pm 0.2 \mathrm{a}$ & $914 \pm 3 \mathrm{a}$ \\
Arsenate & $1.08 \pm 0.12 \mathrm{a}$ & $0.86 \pm 0.06 \mathrm{a}$ & $69.3 \pm 1.0 \mathrm{a}$ & $547 \pm 5 \mathrm{~b}$ \\
DMAA & $0.05 \pm 0.02 \mathrm{~b}$ & $0.08 \pm 0.03 \mathrm{~b}$ & $50.2 \pm 0.5 \mathrm{~b}$ & $484 \pm 5 \mathrm{c}$ \\
\hline
\end{tabular}

${ }^{a}$ Different letters indicate significant differences $(p<0.05)$ between treatments according to the least significant difference (LSD). 


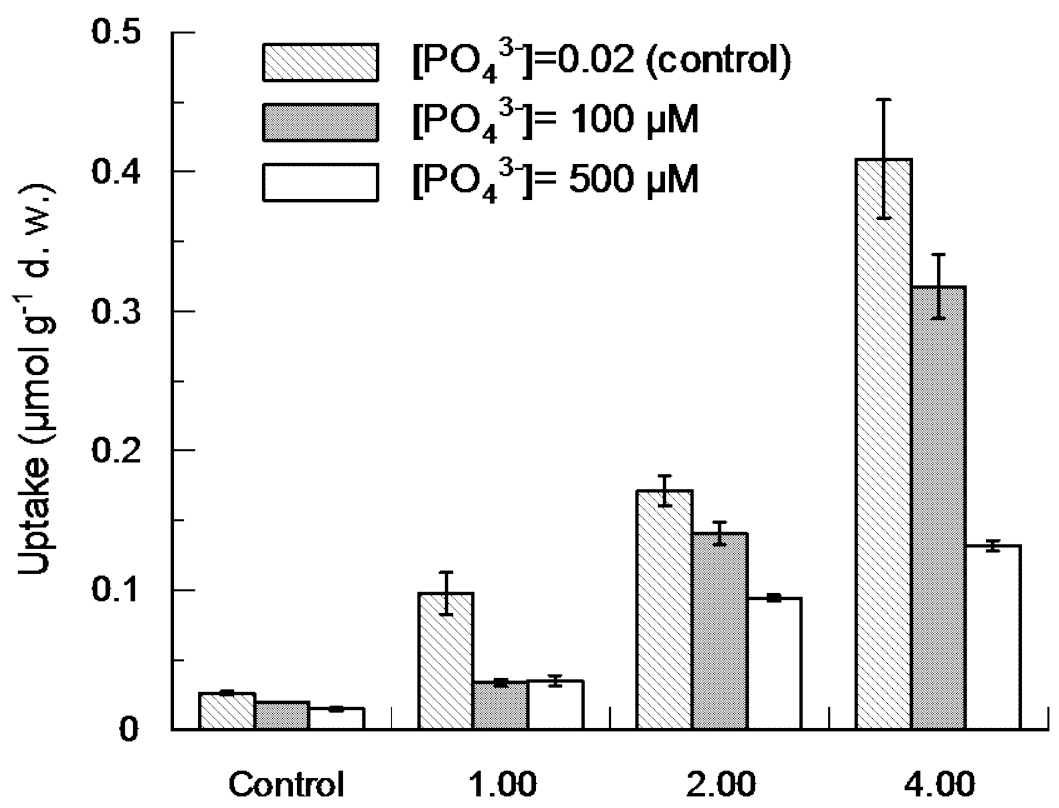

Arsenate concentrations in culture solution $(\mu \mathrm{M})$

Figure 1: Arsenate uptake in S. polyrhiza L. affected by the $\mathrm{PO}_{4}{ }^{3-}$ concentrations in culture solution. Each point is the average of three replicates. Error bars represent \pm SD $(n=3)$. 


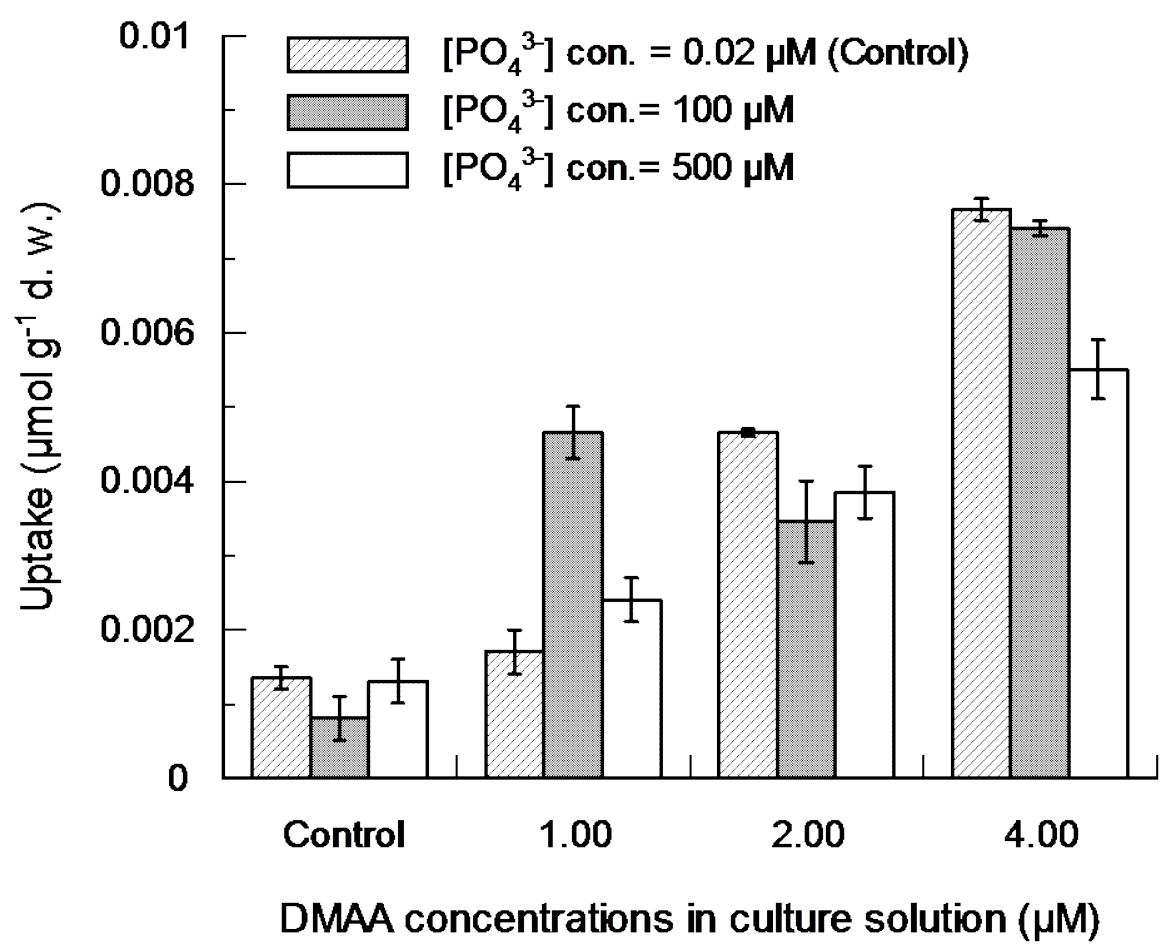

Figure 2: DMAA uptake in S. polyrhiza L. affected by the $\mathrm{PO}_{4}{ }^{3-}$ concentrations in culture solution. Each point is the average of three replicates. Error bars represent \pm SD $(n=3)$. 


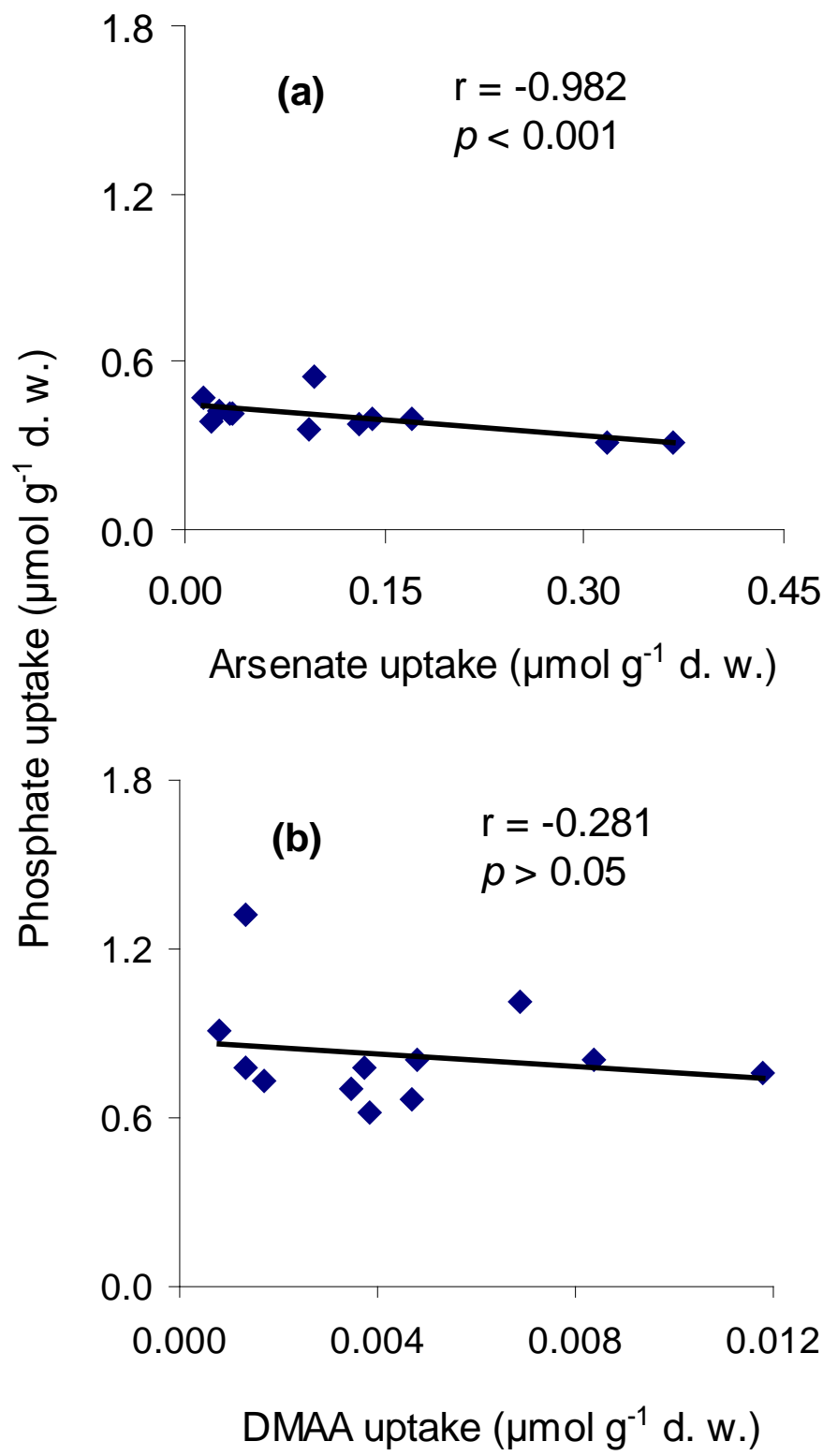

Figure 3: Relationship between arsenic and phosphate uptake in S. polyrhiza L. when the plant was exposed to arsenate (a) and DMAA (b). 


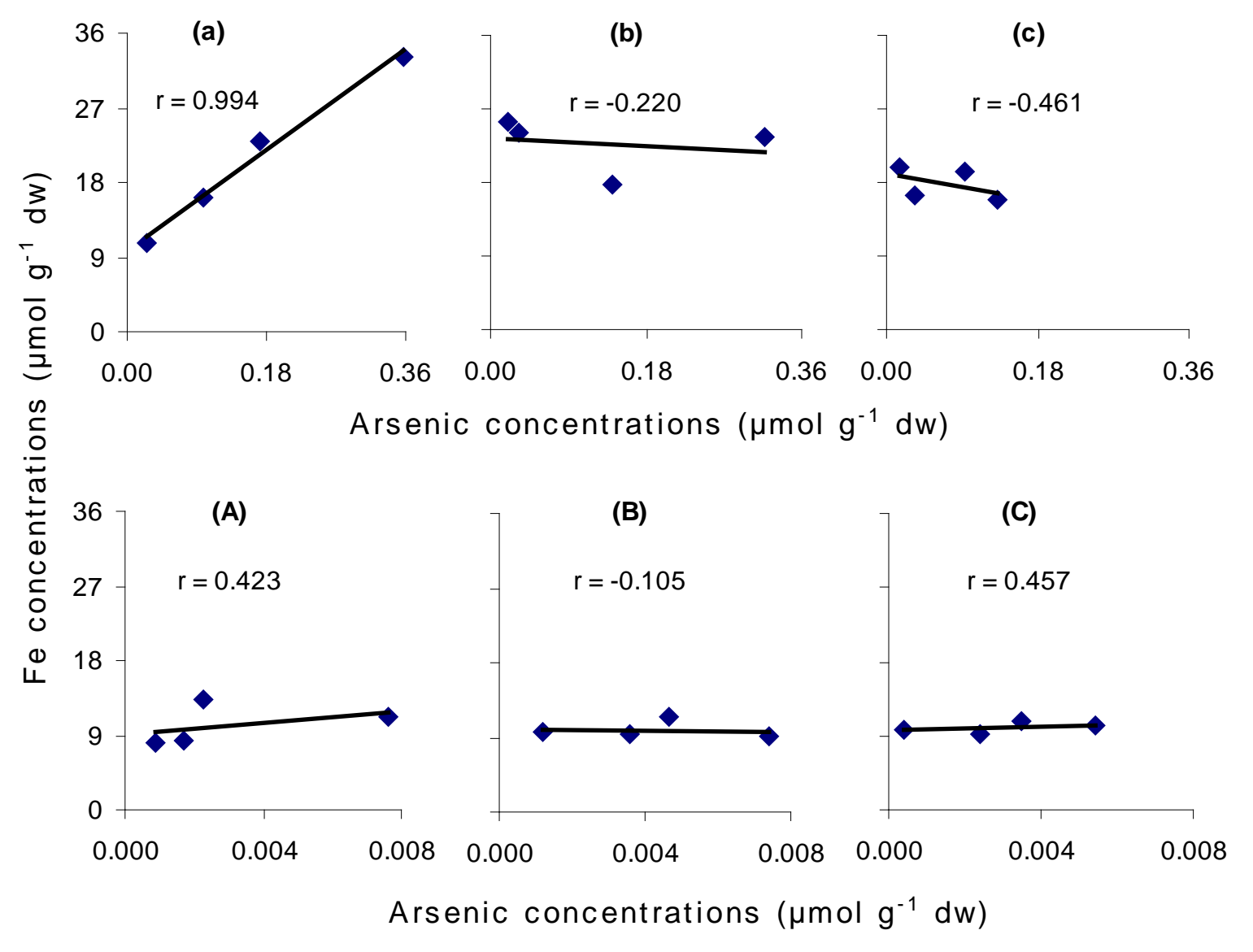

Figure 4: Correlation between arsenic and iron concentrations in S. polyrhiza L. when the plant was exposed to arsenate (above) and DMAA (bellow). $\mathrm{PO}_{4}{ }^{3-}=0.02 \mu \mathrm{M}$ (a, A); $\mathrm{PO}_{4}{ }^{3-}=100 \mu \mathrm{M}(\mathrm{b}, \mathrm{B}) ; \mathrm{PO}_{4}{ }^{3-}=500 \mu \mathrm{M}(\mathrm{c}, \mathrm{C})$. 